\title{
Thermo-mechanical Degradation and VOC Emission of Unstabilized and Stabilized Polypropylene Copolymer During Multiple Extrusions
}

\author{
Carlos Alberto Cáceres ${ }^{\mathrm{a} *}$, Leonardo Zborowski ${ }^{\mathrm{a}}$,Sebastião Vicente Canevarolo \\ aPrograma de Pós-Graduação em Ciência e Engenharia de Materiais - PPG-CEM, \\ Universidade Federal de São Carlos - UFSCar, Rod. Washington Luís, Km 235, \\ CEP 13560-905, São Carlos, SP, Brazil \\ ${ }^{b}$ Departamento de Engenharia de Materiais - DEMa, Universidade Federal de São Carlos - UFSCar, \\ Rod. Washington Luís, Km 235, CEP 13560-905, São Carlos, SP, Brazil
}

Received: August 11, 2011; Revised: September 22, 2011

\begin{abstract}
The thermo-mechanical degradation during the multi-extrusion of unstabilized and stabilized polypropylene copolymer (cPP) was analyzed using the Chain Scission Distribution Function (CSDF) method. During the first extrusion of unstabilized cPP almost $60 \%$ of the initial polymeric chains were submitted to chain scission. The calculations using CSDF show a random chain scission process of chains with molecular weight below $100 \mathrm{~kg} \cdot \mathrm{mol}^{-1}$, and above that a preferential chain scission process. When stabilized the cPP molecular weight is kept constant, even after four extrusions, independently of the stabilizers concentration used. Its chain scission is greatly reduced, only being noteworthy at high values of molecular weight, presenting in this case a preferential chain scission process. During extrusion the unstabilized cPP evolves Volatile Organic Compounds (VOC) due to the volatilization of low molecular weight oxidized chain segments. VOC's emissions are greatly reduced during the melt processing of stabilized cPP, even after multiple extrusions.
\end{abstract}

Keywords: extrusion, thermo-mechanical degradation, polypropylene copolymer, VOC

\section{Introduction}

Polypropylene versatility became it one of the most important thermoplastic materials nowadays, with several applications as commodity plastic or as engineering material ${ }^{1}$. Extrusion is a conventional process in polymer transformation used in mixing, homogenization and the conformation of final products. The molten polymer during extrusion is submitted to high shear rate, high temperature and consequently may undergo structural modifications, mainly chain scission, generally accompanied with deterioration of the physical and mechanical properties ${ }^{2}$.

Suitable stabilization systems can be used to prevent or inhibit these deleterious effects by interfering with the degradation mechanisms. Usually the different types of stabilizers are molten mixed into the polymeric mass, via polymer extrusion. Several commercial antioxidant packages are based on combinations of two or more antioxidants which act as radical and/or hydroperoxide decomposers, and frequently their function can be improved by complementary anti-oxidant mechanisms, with synergistic effects $^{3}$. Hindered amines, which act as radical scavenger during photochemical degradation, are consumed during the thermooxidative degradation due to side reactions with the radicals present in the molten polymer. A good side effect is their action as processing stabilizer ${ }^{4}$. The undesirable HALS consumption during PP processing reduces the performance of the final product. Knowledge on the interactions among additives contributes significantly to improved polymer stabilization ${ }^{5}$. The interactions involving mixtures containing stabilizers as hindered amines and phosphates during polypropylene processing $^{6}$, and among different classes of hindered amines ${ }^{7}$ has been already analyzed, however there are few documents referring the mixture of the three classes of stabilizers during the extrusion or reprocessing, particularly their lost in terms of emissions of volatile organic compounds (VOC).

Volatile organic compounds are products formed during the thermo-mechanical degradation of a polymer, which particularly in the case of polypropylene can be chain fragments, impurities and fragments of different classes of additives ${ }^{8,9}$. Adams et al. ${ }^{10}$ collected particulates and volatile organic compounds emissions during the PP extrusion. The VOC's included aliphatic (ethane, ethylene, propylene) and oxygenated compounds (aldehydes, ketones and carboxylic acids). The most common components found were particulates and VOC's, meanwhile oxygenated compounds appeared in lower concentrations, with emission rates directly proportional to the extrusion temperature. El Mansouri ${ }^{11}$ found that Irganox 1010 degrade into di-tert-butyl-p-hydroxytoluene (BHT) in the ratio of one molecule of Irganox for four molecules of BHT.

Pyrolysis products characteristic of stabilizers also have been analyzed. Wang ${ }^{12}$ presented Irganox 1010 and Irgafos 168 pyrolysis characteristic groups. In the first case, they found methylphenols, ethylphenols and vinylphenols, meanwhile in Irgafos 168 pyrolysis, there are substituted benzenes, toluenes and butylphenols. Hsiao et al. ${ }^{13}$ studied polymer additives analysis using mass spectroscopy and found that in the midst of possible Tinuvin 770 fragments products were trimethyl piperidinyl ring, piperidinyl ring fragments, cleaved ester molecules and fragmented molecules at $\mathrm{CH}_{2}$ groups. Coulier et al. ${ }^{14}$ analyzed the pyrolysis of polymeric HALS, and in the case of oligomeric Chimassorb 944, the main products were trimethyl piperidinyl ring and the monomer unit.

The size exclusion chromatography (SEC) is a helpful tool to study the thermo-mechanical degradation of polymer during extrusion $^{15-20}$. To quantify the intensity of degradation the average 
number of chain scission $\left(n_{s}\right)$ can be calculate from Equation $1^{16,21,22}$. The $n_{s}$ is calculated from the ratio of number average molecular weight the non-degraded and degraded polymer expressed by $\bar{M}_{n(0)}$ and $\bar{M}_{n(f)}$, respectively.

$$
n_{s}=\frac{\bar{M}_{n(0)}}{\bar{M}_{n(f)}}-1
$$

The number of chains scission can be extended for the whole range of the molecular weight distribution (MWD), calculating for each molecular weight of the MWD curve (Equation 2).

$$
N_{s}=\frac{M_{i(0)}}{M_{i(f)}}-1
$$

Where $N_{s}$ is the chains scission curve ${ }^{15,16}, M_{i(0)}$ is a particular value of molecular weight of the MWD curve of the non-degraded polymer and $M_{i(f)}$ its corresponding value in the MWD curve after the polymer undergo a degradation process.

The MWD curve of a polymer shifts away from its original position according to the degradation type and extent. To better understand the polymer degradation processes occurring during extrusion, we have introduced a methodology called Chain Scission Distribution Function (CSDF) ${ }^{15,16}$. The CSDF can be calculated from $N_{s}$ according to Equation 3.

$$
C S D F=\log \left(N_{s}+1\right)=\log \left(M_{i(0)}\right)-\log \left(M_{i(f)}\right)
$$

The CSDF methodology quantifies the shift of the MWD curve of the polymer after thermo-mechanical degradation during the extrusion process, compared to the MWD curve of the non-processed polymer. The shape of the CSDF curve also carries other information i.e. the type of the changes in the polymer chain being either chain scission or chain branching ${ }^{16-18}$. Pinheiro et al. ${ }^{18}$ studied the thermomechanical degradation of HDPE during extrusion applying the CSDF methodology to evaluate the simultaneous mechanisms of chain scission and branching. The chain branching (value of CSDF $<0$ ) predominates during the degradation of HDPE chains with low molecular weight and, on the contrary, chain scission (value of CSDF > 0) dominates in chains having high molecular weight. Thermo-mechanical degradation during extrusion of commercials grades of PP also was studied via CSDF method and the predominant mechanism in all MWD curve extent is only chain scission ${ }^{16,19,20}$.
In this work the thermo-mechanical degradation during the extrusion of unstabilized and stabilized polypropylene copolymer was studied. The stabilization system consists of one primary and one secondary antioxidant, beside two hindered amine light stabilizers. Changes in the molecular weight of the copolymer polypropylene were analyzed via the Chain Scission Distribution Function (CSDF) procedure and the volatile organic compounds (VOCs) evolved during extrusion were analyzed by Infrared Spectroscopy.

\section{Experimental}

\subsection{Materials}

The polymer was a random polypropylene copolymer (cPP) RP347, collected directly from the reactor without having any additive added, produced and kindly donated by BRASKEM, Brazil. The stabilizers were a phenolic primary antioxidant (Irganox $1010^{\circledR}$ ) with molar mass MM of 1178 g.mol ${ }^{-1}$, a phosphate secondary antioxidant (Irgafos $168^{\circledR}$ ) with MM of 646.9 g.mol ${ }^{-1}$, a low molecular weight HALS (Tinuvin $770^{\circledR}$ ) with MM of 481 g. $\mathrm{mol}^{-1}$, and a polymeric HALS (Chimassorb $944^{\circledR}$ ) with MM of $2300 \mathrm{~g} \cdot \mathrm{mol}^{-1}$. These stabilizers were gently provided by BASF S.A., Brazil and used as received. The four stabilizers were individually incorporated in pure cPP using a high rotation speed homogenizer Drais ( $\mathrm{MH}$ Industries) model $\mathrm{MH}-250 \mathrm{H}$ forming master batches of $\mathrm{cPP}$ and a single stabilizer. After melt mixing the molten master batch was immediately hot pressed at $180^{\circ} \mathrm{C}$, cooled in a water bath and grinded in a KIE knife-mill, model MAK 250. Enough quantity of the four master batches was weighted, manually tumbled with pure cPP pellets and fed into the extruder.

\subsection{Extrusion}

The mixtures of the master batches and cPP pellets were melt mixed in a modular co-rotating intermeshing Werner \& Pfleiderer ZSK30 extruder, with gravimetric K-Tron feeder, producing the stabilized cPP formulations with two levels of concentration: 0.2 and $0.4 \%$ (w/w) of each stabilizer. Each stabilized formulation was reprocessed several times. The screw profile used during extrusion is show in the Figure 1. The processing conditions, kept constant throughout all the extrusions were: screw rotation speed of $100 \mathrm{rpm}$, polymer feeding rate of $5 \mathrm{~kg} / \mathrm{h}$, a constant barrel temperature profile and die fixed at $200{ }^{\circ} \mathrm{C}$. The volatile organic compounds (VOC) were trapped by a "cold finger", fitted at the degassing zone of the W\&P

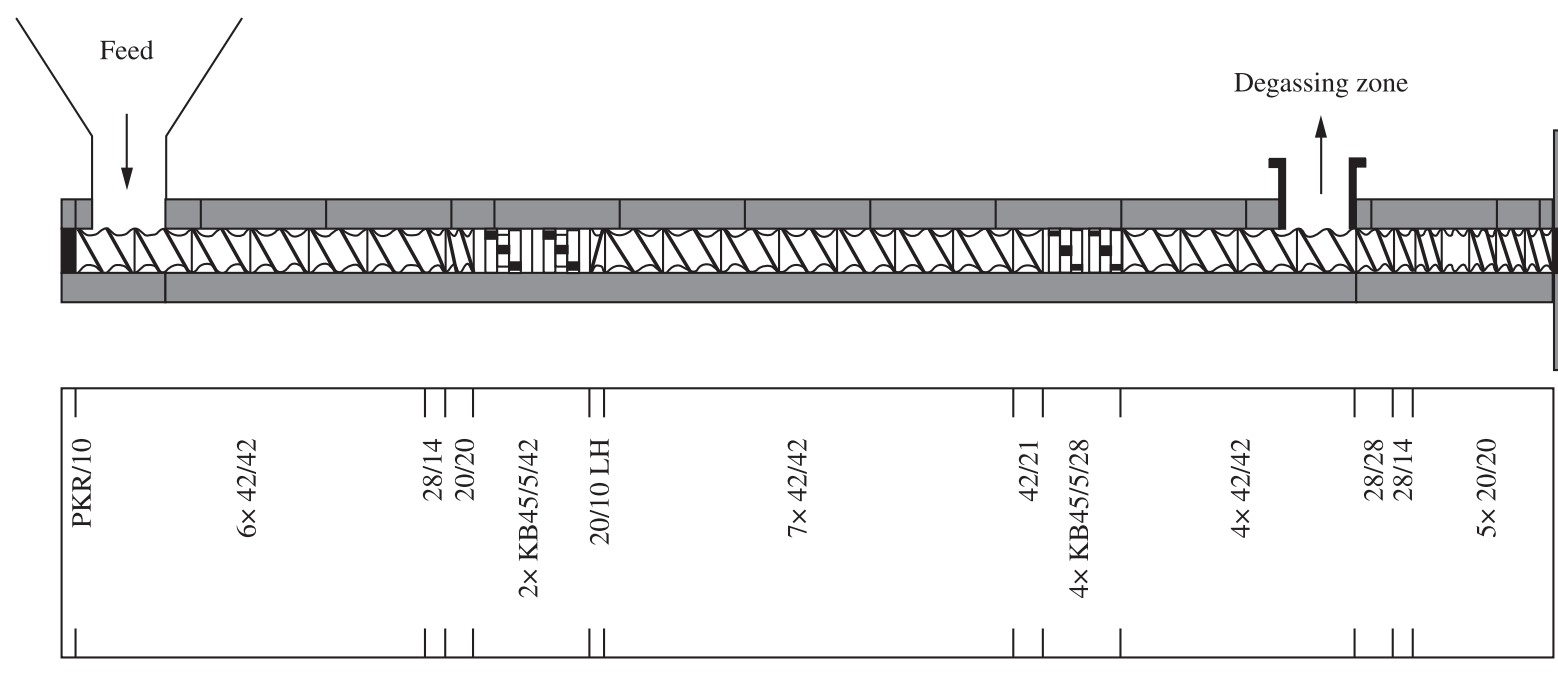

Figure 1. Screw profile used during extrusion. 
extruder, during twelve minutes of extrusion, corresponding to $1 \mathrm{~kg}$ of extruded polymer. The condensed material was collected by washing it out with $20 \mathrm{~mL}$ of chloroform and the solution volume reduced to $1.5 \mathrm{~mL}$ by evaporation at room temperature.

\subsection{Polymer and VOC characterization}

The molecular weight distribution (MWD) curves were obtained in a Waters GPC 150-CV chromatograph with refractive index detector using three Waters Styragel HT columns separating molecular weights from $10^{2}$ to $10^{6} \mathrm{~g} \cdot \mathrm{mol}^{-1}$. The samples were solubilized in 1,2,4-triclorobenzene (TCB) with Irganox 1010 antioxidant at $140{ }^{\circ} \mathrm{C}$, filtered and injected in a flow of $1 \mathrm{~mL} / \mathrm{min}$. The displacement of the MWD curves in relation of the initial MWD curve was calculated using the Chain Scission Distribution Function (CSDF) procedure presented elsewhere ${ }^{16}$ using the CSDF 4.1 software, which is valuable to anyone, just ask the authors.

The characterization of the cPP extrudates was done by infrared spectroscopy using a Perkin-Elmer spectrometer model Spectrum 1000. The samples were hot-pressed at $190{ }^{\circ} \mathrm{C}$ during 60 seconds using spacers in order to produce films with a fixed thickness of $240 \mu \mathrm{m}$. This pressing condition was chosen in order to reduce as much as possible the thermal degradation during the preparation of the films. All spectra were measured in the range of $4000-400 \mathrm{~cm}^{-1}$ at a resolution of $4.0 \mathrm{~cm}^{-1}$ after 32 scans.

The concentrated solutions containing the volatile organic compounds ( $\mathrm{VOC}$ 's $/ \mathrm{CHCl}_{3}$ ) were analyzed using the ATR accessory of the FTIR spectrometer. The infrared spectra were obtained using a cell of $\mathrm{ZnSe}$ (incidence angle at $45^{\circ}$ ). All spectra were measured in the range of $4000-700 \mathrm{~cm}^{-1}$ at a resolution of $4.0 \mathrm{~cm}^{-1}$ and 10 scans.

\section{Results and Discussion}

\subsection{Characterization of the thermo-mechanical degradation of the polypropylene copolymer}

\subsubsection{Molecular weight distribution curves}

The averages molecular weights, polydispersity index, chains scission number $\left(n_{s}\right)$, and melt flow rate (MFR) are presented on Table 1. The thermo-mechanical degradation imposed by the extrusion process in the virgin $\mathrm{cPP}(\mathrm{cPP}-1 \times)$, which has no stabilizer, was enough to reduce nearly $40 \%$ the value of the weight average molecular weight $\left(\bar{M}_{w}\right)$ and approximately $60 \%$ of the initial chains were undergone to at least one chain scission $\left(n_{s}=0.6\right)$. On the other hand, when the cPP is stabilized with 0.2 and $0.4 \% \mathrm{w} / \mathrm{w}$ of each stabilizer it can be reprocessed up to four times, showing a minimum variation in $\bar{M}_{w}$ within the experimental error of the SEC. The melt flow rate (MFR) measurements corroborate the results indicating that the stabilized polypropylene copolymer presents only $1 \%$ difference in the second extrusion and about $4 \%$ in the fourth extrusion. The $n_{s}$ values closed to zero indicate a minimum level of chain scission during the extrusion.

Figure 2 shows the MWD curves of virgin polypropylene copolymer (cPP) and after one extrusion $(\mathrm{cPP}-1 \times)$. The thermomechanical degradation produces an intense displacement of the MWD curve in the direction of the lower molecular weight range. On the other hand, upon stabilization the polypropylene copolymer after reprocessing $(2 \mathrm{x}$ and $4 \mathrm{x})$ showed a very low displacement in the MWD curves, seen in Figure 3, which is difficult to be seen and judged. In order to obtain a better view of MWD curves shift the CSDF methodology was applied and presented subsequently.

\subsubsection{Chain scission distribution function, CSDF}

The thermo-mechanical degradation process of cPP during extrusion was analyzed by CSDF curves and is shown in Figure 4. The CSDF curve obtained from the unstabilized cPP $-1 \times$ after only one extrusion shows a high level of chain scissions. The curve is kept approximately constant up to $\log (\mathrm{MW})=5$ at the 0.15 level. This result indicates a random process of chain scission in molecules with molecular weight up to $100 \mathrm{~kg} . \mathrm{mol}^{-1}$, i.e., the number of scission is independent of the original molecular weight of the chain. For molecular weight above $100 \mathrm{~kg} \cdot \mathrm{mol}^{-1}$ the CSDF curve steps up to $\mathrm{CSDF}=0.3$ indicating that the chain scission mechanism has become preferential, i.e., the number of chain scission increases with the increase of the original molecular weight of the chain. The shape of the CSDF curve indicates that the thermo-mechanical degradation of unstabilized cPP is of a mixed type, random and preferential, depending of the original length of the chain. The CSDF values, ranging from 0.15 up to 0.3 , indicate an elevated number of chain scissions, i.e. a great level of thermo-mechanical degradation after only one extrusion.

Upon stabilization with the four stabilizers used (at 0.2 and $0.4 \% \mathrm{w} / \mathrm{w}$ of each stabilizer) the thermo-mechanical degradation is greatly reduced, even when the reprocessing is taken up to four times. The CSDF values are low, in the range up to 0.07 , indicating a low level of chain scission, almost independent of the number of extrusions and stabilizers concentration. This effect can be due to the synergistic behaviour between HALS and phosphite, as shown by Al-Malaika's group ${ }^{6}$. The shape of the CSDF curves indicates that only chains with very high molecular weight do show a weak but preferential chain scission process. Again the longer chains (higher molecular weights) are the ones more prone to suffer scission due to the higher level of chain entanglements. Is difficult to judge but the $100 \mathrm{~kg} \cdot \mathrm{mol}^{-1}$ critical molecular weight level seems to still holds which is in agreement with previous publications ${ }^{15-17}$.

\subsubsection{Infrared spectroscopy}

Figure 5 presents the IR spectra of hot-pressed films of unstabilized cPP virgin and after been processed once, in the 1800 to $700 \mathrm{~cm}^{-1}$ range. All characteristic bands of the polypropylene

Table 1. Average molecular weight, polydispersity $\left(\bar{M}_{z} / \bar{M}_{w}\right)$, chain scission number $\left(n_{s}\right)$, and melt flow rate (MFR) of multi-extruded polypropylene copolymer.

\begin{tabular}{|c|c|c|c|c|c|c|}
\hline Samples & $\begin{array}{c}\bar{M}_{n} \\
\left(\mathrm{~kg} \cdot \mathrm{mol}^{-1}\right)\end{array}$ & $\begin{array}{c}\bar{M}_{w} \\
\left(\mathrm{~kg} \cdot \mathrm{mol}^{-1}\right)\end{array}$ & $\begin{array}{c}\bar{M}_{z} \\
\left(\mathrm{~kg} \cdot \mathrm{mol}^{-1}\right)\end{array}$ & $\bar{M}_{w} / \bar{M}_{n}$ & $n_{s}$ & $\begin{array}{c}M F R \\
\text { (g/10 minutes) }\end{array}$ \\
\hline $\mathrm{cPP}$ & 51 & 190 & 630 & 3.7 & - & 16.7 \\
\hline $\mathrm{cPP}-1 \times$ & 32 & 120 & 270 & 3.8 & 0.59 & - \\
\hline $\operatorname{cPP}(0.2 \%)-2 \times$ & 58 & 200 & 610 & 3.4 & -0.12 & 9.9 \\
\hline $\operatorname{cPP}(0.2 \%)-4 x$ & 51 & 190 & 580 & 3.7 & 0.00 & 10.4 \\
\hline $\operatorname{cPP}(0.4 \%)-2 \times$ & 52 & 180 & 520 & 3.5 & 0.00 & 9.7 \\
\hline $\operatorname{cPP}(0.4 \%)-4 \times$ & 56 & 200 & 630 & 3.6 & -0.09 & 9.9 \\
\hline
\end{tabular}




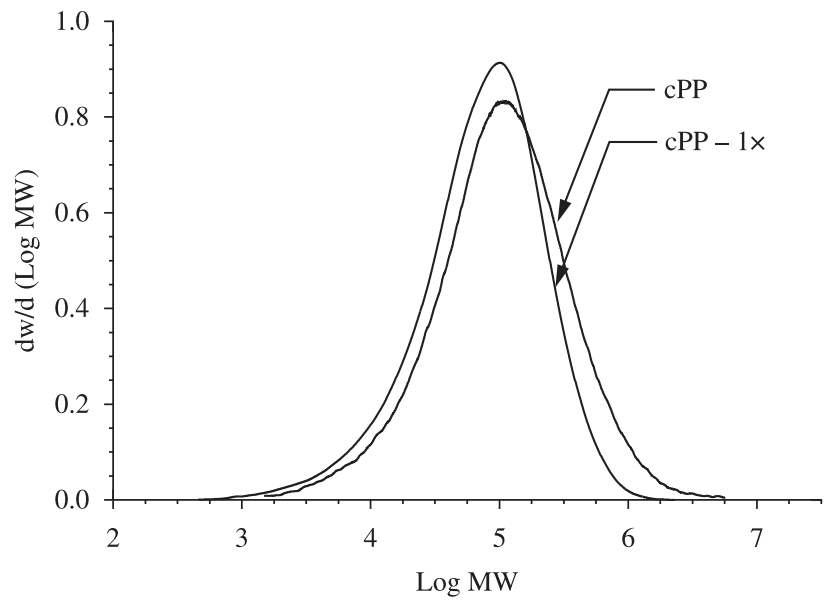

Figure 2. Molecular Weight Distribution curves of unstabilized polypropylene copolymer virgin $(\mathrm{cPP})$ and after one processing $(\mathrm{cPP}-1 \times)$ in an extruder.

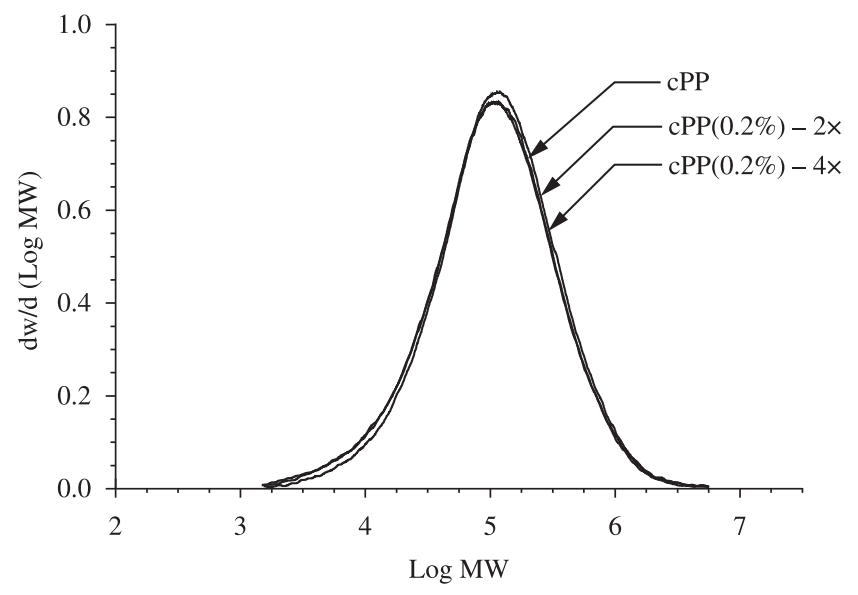

(a)

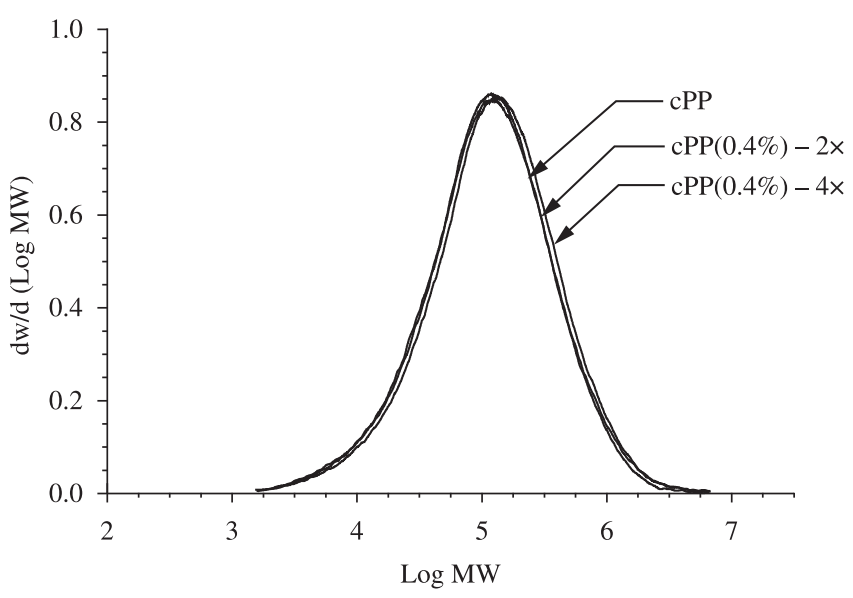

(b)

Figure 3. Molecular Weight Distribution curves of stabilized polypropylene copolymer, virgin (cPP), after two $(2 x)$ and four times $(4 x)$ reprocessed in an extruder: a) $0.2 \% \mathrm{w} / \mathrm{w}$ stabilizers concentration; and in b) $0.4 \%$

chains are present including the band at $720 \mathrm{~cm}^{-1}$, which is due to a sequence of at least two ethylene mers confirming it to be a propyleneethylene copolymer. The lack of the doublet at this band indicates that the ethylene sequences are short and not able to crystallize. The spectra of the virgin cPP will be used as the reference over which

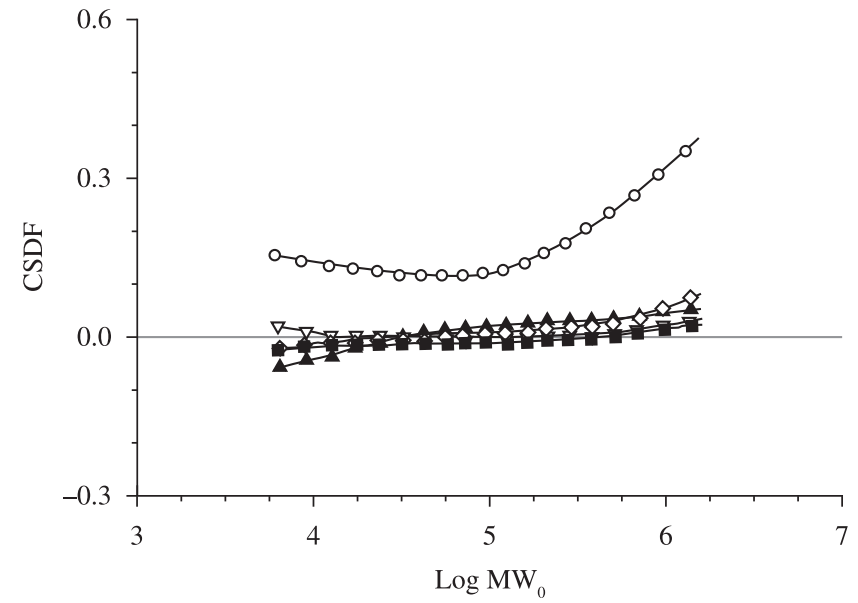

$\multimap-\mathrm{cPP}-1 \times \quad \longrightarrow \mathrm{cPP}(0.2 \%)-2 \times \rightarrow \mathrm{cPP}(0.2 \%)-4 \times$
$\multimap \mathrm{cPP}(0.4 \%)-2 \times \rightarrow \mathrm{cPP}(0.4 \%)-4 \times$

Figure 4. Chain Scission Distribution Function of unstabilized and stabilized polypropylene copolymer. The polymers were multi-processed up to 4 times in an extruder, as indicated.

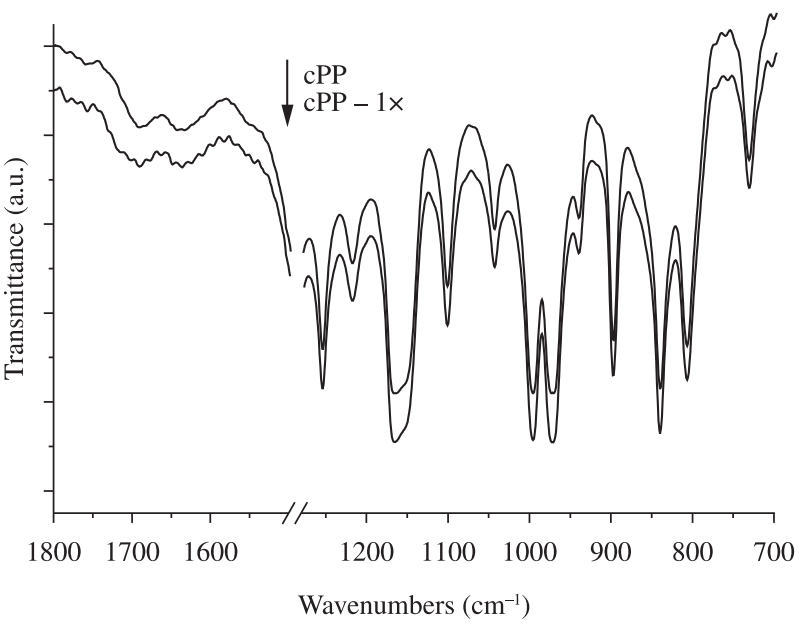

Figure 5. IR spectra of virgin (cPP) and once processed (cPP $-1 \times)$ unstabilized polypropylene copolymer films showing the absorption band at $720 \mathrm{~cm}^{-1}$ due to the short ethylene mer sequences.

the bands of the stabilizers will be identified. After one extrusion the cPP thermo-mechanical degradation, as shown in Figure 4, heavily reduces the molecular weight of the $\mathrm{cPP}-1 \times$ sample, but does not produces significant changes in the IR spectra. The expected level of oxidation, seen in the carbonyl absorption range (1800 to $1700 \mathrm{~cm}^{-1}$ ), is not measurable, indicating that the oxygen content inside the extruder and available to react with the radical chains is low enough to avoid the formation of measurable carbonyl quantities by the FTIR technique. This has been already seen previously in the works of Gonzáles $^{2}$ and Babeto ${ }^{23}$ were low levels of carbonyl were detected after multi-reprocessing PP in an extruder.

Figure 6 presents the IR spectra of stabilized cPP samples in the two additive concentrations Figure $6 \mathrm{a}$ at $0.2 \%$ and Figure $6 \mathrm{~b}$ at $0.4 \%$. In it is seen an intense band at $1738 \mathrm{~cm}^{-1}$ attributed to the ester groups of Irganox 1010. The stabilizer Chimassorb 944 is seen as two bands at 1569 and $1531 \mathrm{~cm}^{-1}$, attributed to the stretching of the ring bond of the triazine group present in the oligomers repeating 
unit. The characteristic bands of Irgafos 168 are at 1083 and $771 \mathrm{~cm}^{-1}$ due to the symmetric axial stretching of the aromatic P-O-C groups. These bands indicate the presence of all stabilizers even after multiple extrusions. In another work ${ }^{24}$ we have shown the high consumption' level of Chimassorb 944 (almost 70\% after three extrusions) and Tinuvin 770 in polypropylene and their role during reprocessing.

Figure 7 shows the IR spectra of the samples at higher wavenumbers, in which is seen an absorption band at $3650 \mathrm{~cm}^{-1}$, which is not present neither in the virgin nor in the unstabilized extruded samples. It is attributed to the $\mathrm{O}-\mathrm{H}$ bond of phenolic antioxidant Irganox 1010, which intensity increases in samples with higher concentration of this antioxidant. These results indicate the presence of this stabilizer in the cPP even after multiple extrusions. In a previous work ${ }^{24}$ we have shown that its consumption is of $42 \%$ after the third extrusion for stabilized cPP with $0.2 \% \mathrm{w} / \mathrm{w}$ and $34 \%$ when the stabilizer concentration was doubled $(0.4 \% \mathrm{w} / \mathrm{w})$.

\subsection{Volatile organic compounds, VOC}

\subsubsection{VOC evolved during the extrusion of unstabilized polypropylene copolymer}

Volatile organic compounds evolved during the extrusion of the polypropylene copolymer were collected by the cold-finger fitted at degassing vent of the extruder, washed out with chloroform and analyzed via FTIR-ATR. Figure 8 shows the spectra of pure chloroform in which its characteristic bands can be seen. The second spectrum presented in this figure is from the chloroform solution containing the VOC evolved during the first extrusion of the unstabilized polypropylene copolymer $(\mathrm{cPP}-1 \times)$. The chloroform bands are well defined and do not interfere with the characteristic bands of the VOC present in the solution. The new bands, produced by the VOC are: the axial deformation of $\mathrm{C}-\mathrm{H}$ at $2958 \mathrm{~cm}^{-1}$

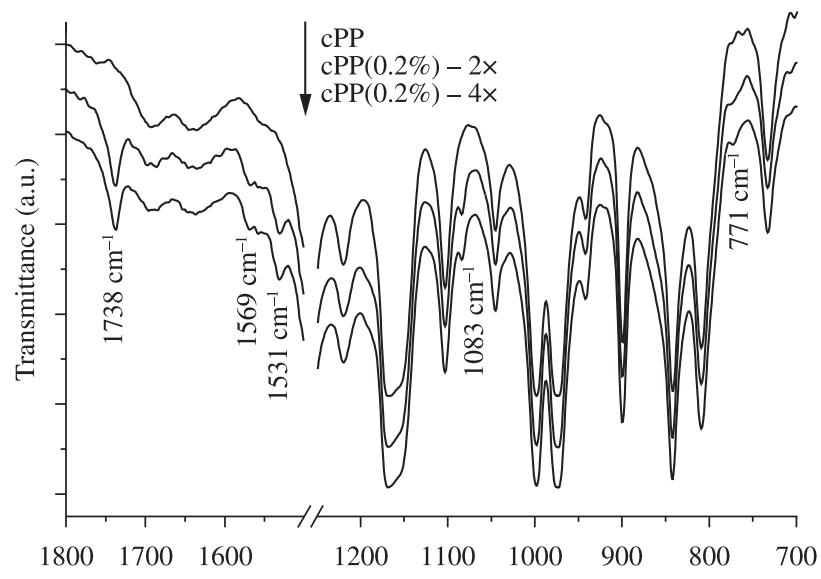

Wavenumbers $\left(\mathrm{cm}^{-1}\right)$

(a)

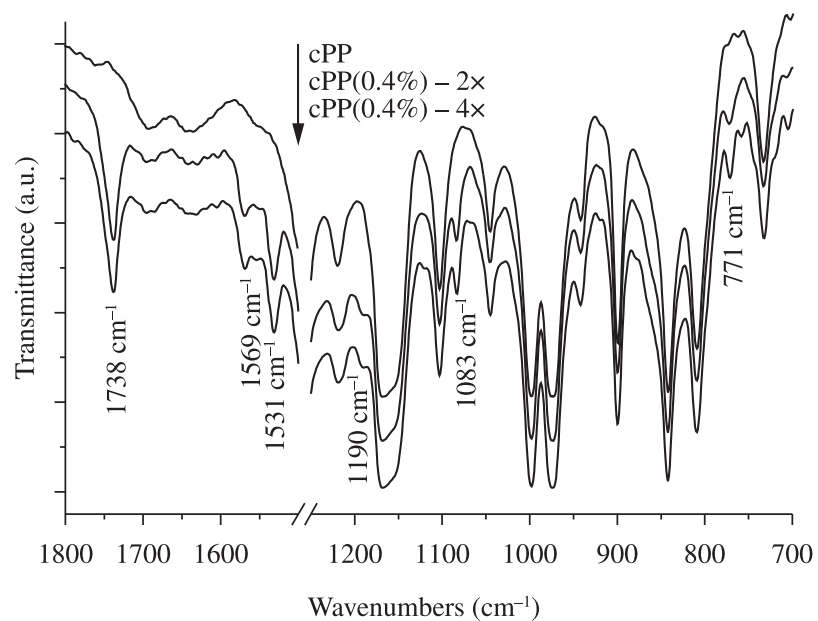

(b)

Figure 6. IR spectra of multi-processed stabilized cPP films with two different additives concentration: a) $0.2 \%$ w/w and b) $0.4 \%$. The absorption band of each added additive is seen in the spectra. See text for the attributions.

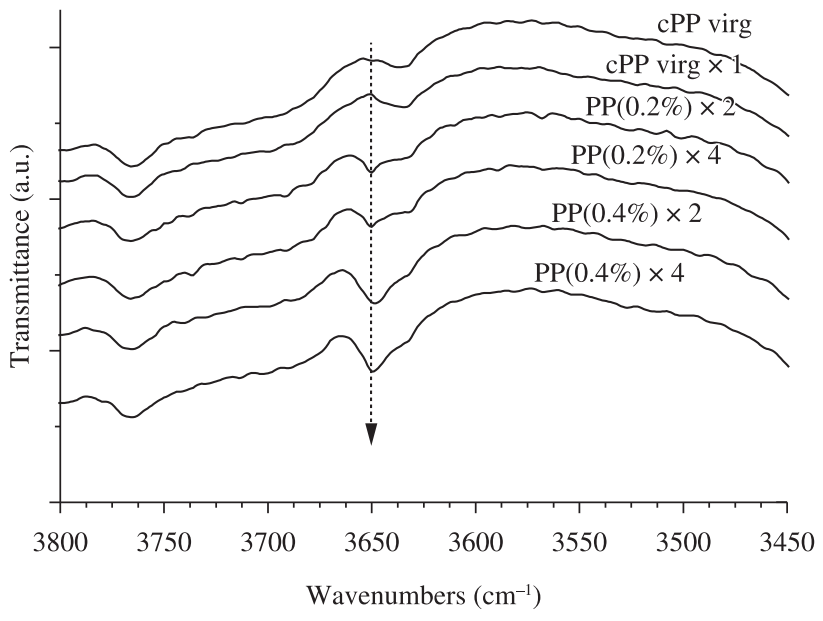

Figure 7. IR spectra of unstabilized and stabilized polypropylene copolymer films after multiple extrusions. The Ar-OH absorption band of Irganox 1010 at $3650 \mathrm{~cm}^{-1}$ is seen only for stabilized samples and is proportional to its concentration.

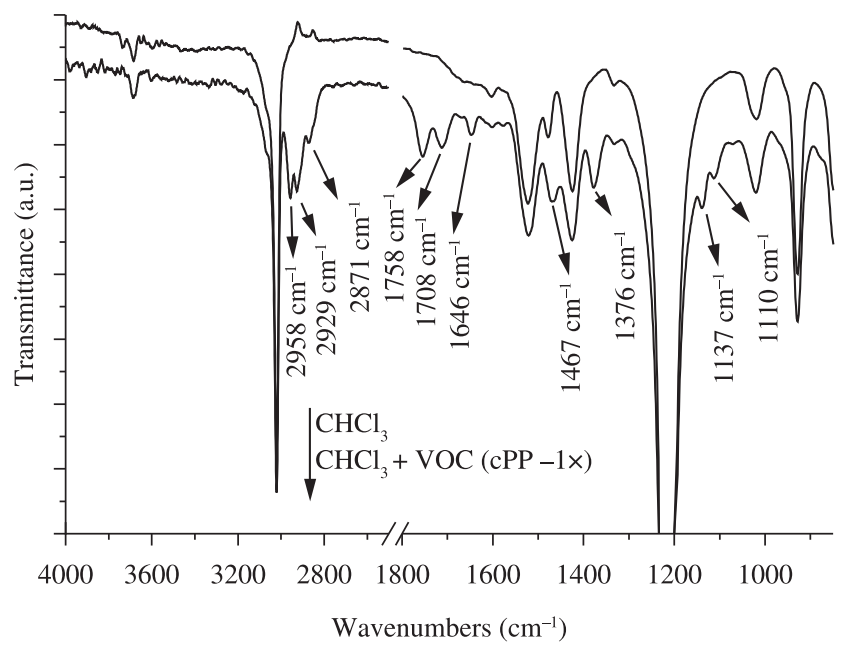

Figure 8. IR spectra of volatile organic compounds VOC's in chloroform solution evolved during extrusion of unstabilized polypropylene copolymer. The pure chloroform is shown in the upper spectrum. 


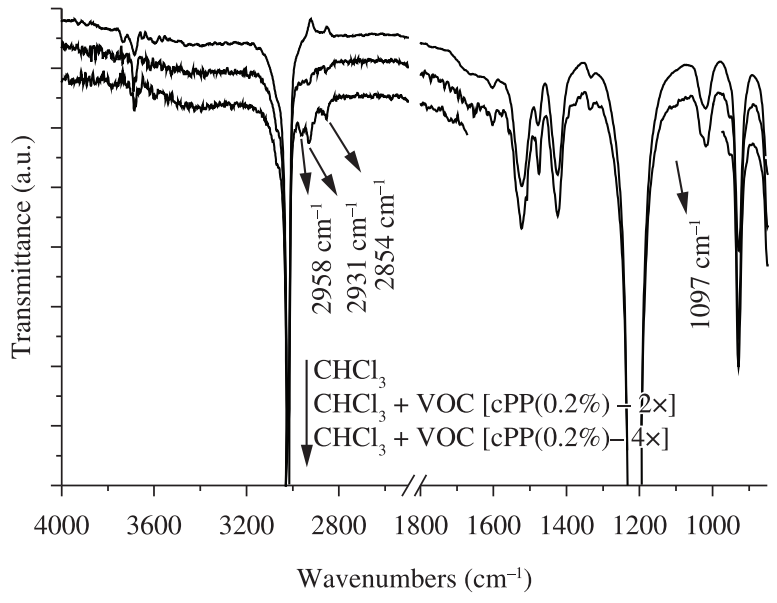

(a)

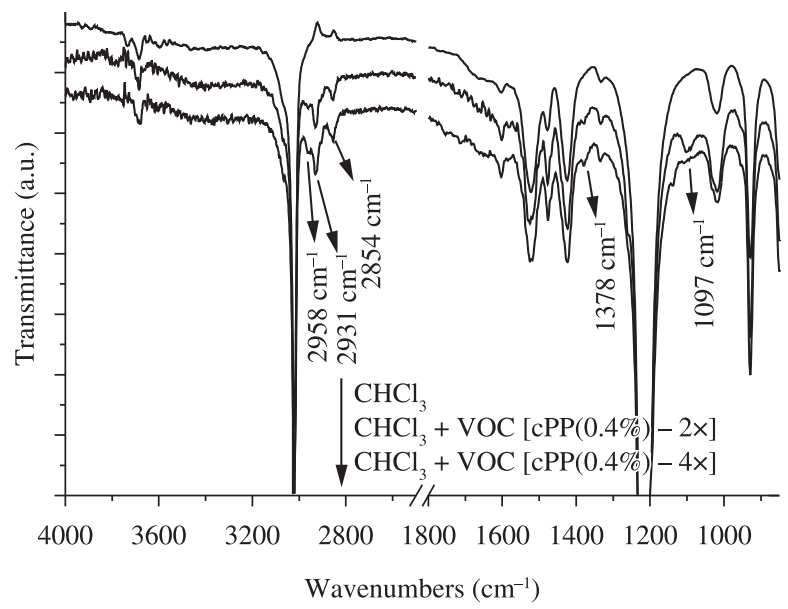

(b)

Figure 9. IR spectra of VOC in chloroform solution evolved during multi-extrusion of stabilized polypropylene copolymer with two different additives concentrations: a) $0.2 \% \mathrm{w} / \mathrm{w}$ and b) $0.4 \%$.

(v $\mathrm{CH}_{3}$ asym), $2871 \mathrm{~cm}^{-1}$ ( $v \mathrm{CH}_{3}$ sym) and $2929 \mathrm{~cm}^{-1}$ (v $\mathrm{CH}_{2}$ sym), angular deformations of $\mathrm{C}-\mathrm{H}$ at $1467 \mathrm{~cm}^{-1}\left(\delta \mathrm{CH}_{2} \mathrm{sym}\right), 1458 \mathrm{~cm}^{-1}$ $\left(\delta \mathrm{CH}_{3}\right.$ asym $)$ and $1376 \mathrm{~cm}^{-1}\left(\delta \mathrm{CH}_{3} \mathrm{sym}\right)$, axial deformation of $\mathrm{C}=\mathrm{C}$ bonds at $1646 \mathrm{~cm}^{-1}$, alcohol vibrations ( $\mathrm{V}-\mathrm{O}$ ) band at $1110 \mathrm{~cm}^{-1}$, a weak absorption band at $1065 \mathrm{~cm}^{-1}$ attributed to aliphatic ethers ( $v$ C-O). A band at $1708 \mathrm{~cm}^{-1}$ can be attributed to aliphatic carboxylic acid ( $v \mathrm{C}=\mathrm{O}$ ) and the band at $1758 \mathrm{~cm}^{-1}$ can be related to the axial deformation ( $v \mathrm{C}=\mathrm{O}$ ) of $\mathrm{R}-\mathrm{O}-\mathrm{CO}-\mathrm{C}-\mathrm{R}$ aliphatic ester groups.

During the extrusion the polymer chains are melted and forced to flow in an ambient with high shear fields, temperature and oxygen. This harsh environment causes the thermo-mechanical degradation of the chains that, in the case of polypropylene, include mainly chain scission and reaction of the radical chain ends with oxygen. The products are mainly shorter polymer chains with oxidized ends, which reduces the averages molecular weight, increases the melt flow rate and tints the degraded polymer in light yellow. During this process a smaller amount of very short chains, oligomers, are also generated and can be pyrolysed from the molten polymer, pumped out by the vacuum at the degassing vent of the extruder as VOC's. These constituents are predominantly alkanes with carbons numbers of 14 to $19^{25}$. If the polymer has no additives, which is the case of the polypropylene copolymer spectra presented in Figure 8, the VOC evolved is composed only by partially oxidized olefinic molecules. Thus the IR-spectra do show the presence of $\mathrm{CH}_{2}, \mathrm{CH}_{3}$, $\mathrm{C}=\mathrm{C}, \mathrm{C}-\mathrm{O}$ and $\mathrm{C}=\mathrm{O}$ bonds in the $\mathrm{VOC}$, indication of short olefinic molecules some of them oxidized forming alcohol, ethers, esters, ketones, and aldehydes.

\subsubsection{VOC evolved during the extrusion of stabilized polypropylene copolymer}

The IR-spectra of VOC's collected during the extrusion of a stabilized polypropylene copolymer are shown in Figure 9. Figure 9a presents data for a concentration of the four stabilizers fixed at $0.2 \%$ and Figure $9 \mathrm{~b}$ the case in which the concentration was doubled to $0.4 \%$. The two sets of curves are quite similar varying only the peak intensities, which are greater in samples with higher stabilizers concentration. The IR-spectra show bands attributed to $\mathrm{C}-\mathrm{H}$ axial deformations at $2931 \mathrm{~cm}^{-1}\left(v \mathrm{CH}_{2}\right.$ asym) and $2854 \mathrm{~cm}^{-1}$ (v $\mathrm{CH}_{2}$ sym), a weak band at $2958 \mathrm{~cm}^{-1}$ attributed to methyl group deformation ( $v \mathrm{CH}_{3}$ asym), another weak band attributed to $\mathrm{C}-\mathrm{H}$ angular deformation at $1378 \mathrm{~cm}^{-1}\left(\delta \mathrm{CH}_{3}\right.$ sym) and at $1097 \mathrm{~cm}^{-1}$ $(\delta \mathrm{P}-\mathrm{H})$ possibly due to Ar-P-H group suggesting the volatilization of Irgafos 168 fragments.

It is also seen in the spectra of the VOC solution got from stabilized cPP an absorption band at $2854 \mathrm{~cm}^{-1}$, which could be attributed to possible presence of Tinuvin 770 fragments. It was not possible to detect an isolated characteristic absorption band of the Tinuvin 770, present in the stabilized cPP films spectra. Tinuvin 770, having the smallest molecular weight and melting point of all added stabilizers, decomposes easier and in greater amounts during the extrusion. Besides, at the extrusion conditions used it is also expected some fragmentation of the other stabilizers due to high shear stresses and temperature common to this environment.

A marked difference between the VOC produced during the extrusion of polypropylene copolymer when protected by the addition of stabilizers is the great reduction in the formation of oxidized volatile organic products. They can be detected by their absorption bands in the range $1800-1700 \mathrm{~cm}^{-1}$, characterizing the efficient protection promoted by the stabilizers against the oxidation of the polymer.

\section{Conclusions}

Thermo-mechanical degradation of unstabilized cPP during extrusion caused scission in $60 \%$ of the initial chains at least once. It reduced the initial $\bar{M}_{w}$ in $40 \%$. With stabilized cPP the average chain scission number was reduced but the molecular weight $\bar{M}_{w}$ is not affected even after four extrusions. The calculated CSDF values of unstabilized cPP showed a random chains scission process for molecular weight up to $100 \mathrm{~kg} \cdot \mathrm{mol}^{-1}$, for higher values a preferential chain scission process is dominant. In the case of stabilized cPP the CSDF values showed that only the higher molecular weight chains do show a preferential chain scission process. At the stabilizers concentration above $0.2 \% \mathrm{w} / \mathrm{w}$ used the CSDF values do not detect any changes in the chain scission number, independent of the number of extrusions. During the extrusion of unstabilized cPP there is the evolution of VOCs emissions, which are degradation products produced during processing. In the case of stabilized cPP the VOCs evolution is kept very low, up to the fourth extrusion.

\section{Acknowledgements}

We acknowledge the financial support from CNPq under various projects. Two of us (C. A. C and L. Z. S.) acknowledge CAPES for the scholarships. 


\section{References}

1. Moore EP. Polypropylene handbook: polymerization, characterization, properties, processing, applications. New York: Hanser, 1996.

2. González VA, Neira G and Angulo JL. Polypropylene chain scission and molecular weight changes in multiple extrusions. Polymer Degradation and Stability. 1998; 60(1):33-42. http://dx.doi.org/10.1016/S01413910(96)00233-9

3. Neri C, Costanzi S, Riva RM, Farris R and Colombo R. Mechanism of action of phosphites in polyolefin stabilization. Polymer Degradation and Stability. 1995; 49(1):65-69. http://dx.doi.org/10.1016/01413910(95)00057-S

4. Schwertlick K and Habicher WD. Antioxidant action mechanisms of hindered amine stabilizers. Polymer Degradation and Stability. 2002; 78(1):35-40. http://dx.doi.org/10.1016/S0141-3910(02)00116-7

5. Reingruber E and Buchberger W. Analysis of polyolefin stabilizers and their degradation products. Journal of Separation Science. 2010; 33:3463-3475. PMid:21086426. http://dx.doi.org/10.1002/ jssc. 201000493

6. Bauer I, Habicher WD, Rautenberg C and Al-Malaika S. Antioxidant interaction between organic phosphites and hindered amine light stabilizers during processing and thermoxidation of polypropylene. Polymer Degradation and Stability. 1995; 48(3):427-440. http://dx.doi. org/10.1016/0141-3910(95)00104-T

7. Gugumus F. Possibilities and Limits of Synergism with Light Stabilizers in Polyolefins 1. HALS in Polyolefins. Polymer Degradation and Stability. 2002; 75(2):295-308. http://dx.doi.org/10.1016/S0141-3910(01)00233-6

8. Xiang Q, Xanthos M, Mitra S, Patel SH and Guo J. Effects of melt reprocessing on volatile emissions and structural/rheological changes of unstabilized polypropylene. Polymer Degradation and Stability. 2002; 77(1):93-103. http://dx.doi.org/10.1016/S0141-3910(02)00083-6

9. Albertsson AC, Gröning M and Hakkarainen M. Emission of Volatiles from Polymers-A New Approach for Understanding Polymer Degradation. Journal of Polymers and the Environment. 2006; 14(1):9-13. http://dx.doi.org/10.1007/s10924-005-8702-2

10. Adams K, Bankston J, Barlow A, Holdren MW, Meyer J and Marchesani VJ. Development of emission factors for polypropylene processing. Journal of the Air \& Waste Management Association. 1999; 49(1):49-56.

11. El Mansouri H, Yagoubi N and Ferrier D. Extraction of polypropylene additives and their analysis by HPLC. Chromatographia. 1998; 48(7):491-496. http://dx.doi.org/10.1007/BF02466639

12. Wang FCY. Polymer additive analysis by pyrolysis-gas chromatography IV. Antioxidants. Journal of Chromatography A. 2000; 891(2):325-336. http://dx.doi.org/10.1016/S0021-9673(00)00647-6

13. Hsiao ST, Tseng MC, Chen YR and Her GR. Analysis of Polymer Additives by Matrix-Assisted Laser Desorption Ionization/Time of Flight
Mass Spectrometer Using Delayed Extraction and Collision Induced Dissociation. J. Chinese Chem. Soc. 2001; 48(6):1017-1027.

14. Coulier L, Kaal ER, Tienstra M and Hankemeier TH. Identification and quantification of (polymeric) hindered-amine light stabilizers in polymers using pyrolysis-gas chromatography-mass spectrometry and liquid chromatography-ultraviolet absorbance detection-evaporative light scattering detection. Journal of Chromatography A. 2005; 1062(2):227-238. PMid:15679160. http://dx.doi.org/10.1016/j. chroma.2004.11.013

15. Canevarolo SV. Chain scission distribution function for Polypropylene degradation during multiple extrusions. Polymer Degradation and Stability. 2000; 70(1):71-76. http://dx.doi.org/10.1016/S01413910(00)00090-2

16. Caceres CA and Canevarolo SV. Calculating the chain scission distribution function (CSDF) using the concentration method. Polymer Degradation and Stability. 2004; 86(3):437-444. http://dx.doi.org/10.1016/j. polymdegradstab.2004.05.014

17. Caceres CA and Canevarolo SV. Chain scission in the thermo-mechanical degradation of polystyrene under multiple extrusions. Polímeros. 2008; 18(4):348-352.

18. Pinheiro LA, Chinelatto MA and Canevarolo SV. The role of chain scission and chain branching in high density polyethylene during thermomechanical degradation. Polymer Degradation and Stability. 2004; 86(3):445-453. http://dx.doi.org/10.1016/j.polymdegradstab.2004.05.016

19. Machado AV, Maia JM, Canevarolo SV and Covas JA. Evolution of peroxide induced thermo-mechanical degradation of polypropylene along the extruder. Journal of Polymer Science. 2004; 91(4):2711-2720.

20. Caceres CA and Canevarolo SV. Correlation between melt flow index and chain scission distribution function during the thermo-mechanical degradation of polypropylene. Polímeros. 2006; 16(4):294-298.

21. Reich L and Stivala S. Elements of Polymer Degradation. New York: McGraw-Hill, 1971.

22. Tobolsky AV, Kotliar AM and Lee TCP. Random Scission Processes. In: Conley RT. Thermal Stability of Polymers. New York: Marcel Dekker; 1970.

23. Babetto AC and Canevarolo SV. Effect of screw elements on the polypropylene degradation during multiple extrusions. Polímeros. 2000; 10(2):90-99.

24. Zborowski L, Chinelatto MA and Canevarolo SV. Stabilizers Consumption during Polypropylene Multiple Extrusions. In: Proceedings of the 24th Annual Meeting of The Polymer Processing Society; 2008; Salerno, Italy. Salerno; 2008.

25. Eiceman GA, Bergloff JF and Funk PA. Comparison of emission profiles for volatile organic compounds from cotton and polypropylene-based tarp. Journal of Cotton Science. 2002; 6(1):40-51. 